\title{
Modular Redox Switching of Dinuclear Organometallic Molecular Junctions
}

\author{
Yuya Tanaka, ${ }^{* 1,2 \dagger}$ Naoki Morozumi, ${ }^{2 \dagger}$ Tatsuhiko Ohto, ${ }^{3,4}$ Satoshi Kaneko, 5 Yasuhisa Naitoh, ${ }^{6}$ Hi- \\ rokazu Tada, ${ }^{3}$ Shintaro Fujii, 5 Tomoaki Nishino, ${ }^{5}$ Munetaka Akita*1,2 \\ ${ }^{1}$ Laboratory for Chemistry and Life Science, Institute of Innovative Research, Tokyo Institute of Technology, $4259 \mathrm{Na-}$ \\ gatsuta, Midori-ku, 226-8503, Yokohama, Japan. \\ 2 Department of Chemical Science and Engineering, School of Materials and Chemical Technology, Tokyo Institute of \\ Technology, 4259 Nagatsuta, Midori-ku, 226-8503, Yokohama, Japan. \\ ${ }^{3}$ Graduate School of Engineering Science, Osaka University \\ 1-3 Machikaneyama, Toyonaka, Osaka 560-8531, Japan \\ ${ }^{4}$ Center for Quantum Information and Quantum Biology, Institute for Open and Transdisciplinary Research Initiatives, \\ Osaka University, 1-3 Machikaneyama, Toyonaka, Osaka 560-8531, Japan \\ ${ }_{5}^{5}$ Department of Chemistry, School of Science, Tokyo Institute of Technology, 2-12-1 Ookayama, Meguro-ku, 152-8551, \\ Tokyo, Japan. \\ ${ }^{6}$ National Institute of Advanced Industrial Science and Technology (AIST), Tsukuba, Ibaraki 305-8565, Japan \\ KEYWORDS. single-molecule conductance, redox-responsive molecular switch, mixed-valence species, break junction, \\ ruthenium acetyildes.
}

\begin{abstract}
Molecular switch is one of the essential functional units of molecular electronics. Here, we report development of new molecular switches based on the electron-rich diruthenium complexes with the (2,5-di-R-substituted 1,4diethynylbenzene)diyl linkers. The dinuclear molecular switches, $\left\{\mu-p-\mathrm{C} \equiv \mathrm{C}-\left(2,5-\mathrm{R}_{2}-\mathrm{C}_{6} \mathrm{H}_{2}\right)-\mathrm{C} \equiv \mathrm{C}\right\}\left\{\mathrm{Ru}(\mathrm{dppe})_{2}\left(\mathrm{C} \equiv \mathrm{C}-\mathrm{C}_{6} \mathrm{H}_{4}-p-\right.\right.$ $\mathrm{SMe})\}_{2} \mathbf{1}^{\mathrm{R}}\left(\mathrm{R}=\mathrm{OMe}, \mathrm{H}, \mathrm{CF}_{3}\right)$, with various substituents $(\mathrm{R})$ on the bridging phenylene rings showed two successive reversible 1e-oxidation waves, indicating stability of 1e-oxidized mixed-valence species. The solid-state structure of $\left[\mathbf{1}^{\mathrm{H}}\right]^{+}$showed the charge-localized Robin-Day class II nature, while that of [10Me $]^{+}$revealed the fully charge-delocalized class III nature. These characters were also evident from the spectroscopic data in solutions. Single-molecule conductance measurements by the scanning tunneling microscope break junction method revealed a significant dependence of the conductance on R, i.e. 10Me turned out to be $>100$-times more conductive than $\mathbf{1}^{\mathrm{H}}$ and $\mathbf{1}^{\mathrm{CF} 3}$, whereas the substituent effect of the monocationic complexes was within a fold-change of 2 . As a result, the ON/OFF ratios (the ratios of the conductance of the cationic species $\left[\mathbf{1}^{\mathrm{R}}\right]^{+}$to that of the neutral species $\mathbf{1}^{\mathrm{R}}$ ) were critically dependent on $\mathrm{R}$ (as large as 191 when $\left.\mathrm{R}=\mathrm{CF}_{3}\right)$ and even reversed $(0.4$ when $\mathrm{R}$ $=\mathrm{OMe}$ ). Furthermore, the neutral and monocationic complexes $\mathbf{1}^{\mathbf{H}}$ and $\left[\mathbf{1}^{\mathrm{H}}\right]^{+}$fabricated into the nanogap devices showed in situ ON/OFF switching behavior. The present study demonstrates not only the rare examples of the mixed-valence complexes which were subjected to the break junction measurements but also the first examples of molecular switch, the ON/OFF ratio of which was controlled by tuning the organic linker parts.
\end{abstract}

\section{INTRODUCTION}

Molecular switch, which can control a specific function of itself by an external stimulus reversibly, is an essential part in molecule-based electronics. So far, there have been reports on various molecular switches incorporated into metal-molecule-metal junctions, which are responsive to mechanical, ${ }^{1-3}$ acid-base, ${ }^{4,5}$ photo-irradiation ${ }^{6-8}$, and redox stimuli ${ }^{9,10}$. Redox stimulus is superior to other stimuli due to the easy fabrication of the trigger by installation of a third electrode into nano-devices, in addition to drain and source electrodes. ${ }^{11}$ Some redox-triggered organic molecular switches have been known. Neaton, Venkataraman, and Campos reported an aromatic bifluorenylidene-based redox switch, which was converted to the anti-aromatic dicationic states upon 2e-oxidation (Figure 1a). ${ }^{10}$ A large ON/OFF ratio (the ratio of the conductance of the $\mathrm{ON}$ and OFF states) with a factor of 70 was reported. Multiple switching behavior was reported for the naphthalenediimide derivative (Figure 1b). ${ }^{9}$ Stepwise 1e-reduction led to the mono- and di-anionic states and the monoanionic state showed conductance 10 times higher than that of the neutral state. For the redox switch, however, there remain two key issues to be solved. One is the instability of the oxidized or reduced radical species formed upon application of redox stimuli. The other is lack of rational molecular design to modulate/control the ON/OFF ratio without interfering the original switching function. ${ }^{12}$ 


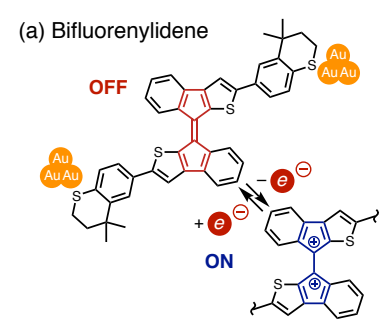

(c) This study substituents
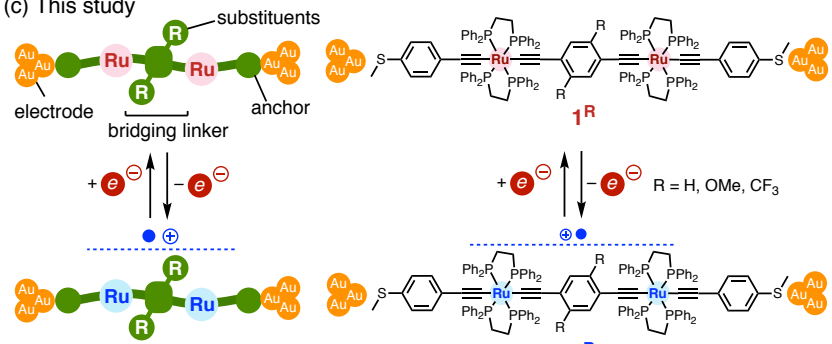

$+e^{\ominus} \mid \downarrow-e^{\ominus} \mathrm{R}=\mathrm{H}, \mathrm{OMe}_{\mathrm{CF}}$

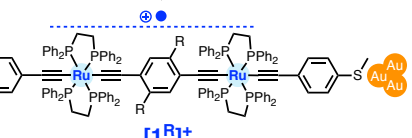

$\left[1^{R}\right]^{+}$

Figure 1. Organic Molecular switches based on (a) bifluorenyllidene and (b) naphthalene diimide. (c) Concept of the present redox-responsive dinuclear molecular switches $\mathbf{1}^{\mathbf{R}}$ $\left[\mathbf{1}^{\mathrm{R}}\right]^{+}\left(\mathrm{R}=\mathrm{OMe}, \mathrm{H}, \mathrm{CF}_{3}\right)$.

Of mixed-valence (MV) species, dinuclear systems are composed of two metal centers with different oxidation states $\left(\mathrm{M} / \mathrm{M}^{\bullet+}\right)$, in many cases, bridged by an organic ligand (BL), ${ }^{13}$ i.e. $\mathrm{M}-\mathrm{BL}-\mathrm{M}^{\bullet+}$, and are considered to be excellent model systems to examine the Marcus-type charge transfer phenomena in solution. A charge carrier can be transferred from one metal center to the other metal center with a different oxidation state through the BL. 1e-Redox process of a closed-shell precursor (M-BL-M) leads to an open-shell MV complex, which may be stabilized by charge delocalization over the [M-BL-M] $]^{\bullet+-}$ backbone. This redox interconversion between the neutral and MV states could be used as a guiding principle for molecular switch not only because the two electronic states are drastically different but also because the charge transfer phenomena can be finely controlled by appropriate combination of the metal fragments and the bridging ligand, which should affect the conductance through the molecular junction based on the MV systems. Furthermore, the effect of charge-localization of MV complexes on the single-molecule conductance study remains elusive.

Transition-metal acetylides are a class of promising candidates for components of molecular electronics as they show highly conducting nature due to the high-lying HOMO energy levels caused by the electron-rich metal fragments with $n d$ electrons. ${ }^{14-17}$ In addition, many of them are redox-active and, therefore, can be the switching triggers. Thus far, the redox-switching behavior of organometallic mononuclear acetylide complexes in nanogaps has been investigated only for in-situ charging/discharging at low temperature. ${ }^{18-20}$ However, no example operated at room temperature has been reported mainly because of the intrinsic instability of the oxidized/reduced open-shell radical species of mononuclear organometallic complexes. ${ }^{21,22}$ Herein we report new redox-switchable dinuclear organometallic complexes based on the electron-rich trans-Ru(dppe) 2 fragments $\mathbf{1}^{\mathbf{R}} \quad$ (dppe: 1,2bis(diphenylphosphino)ethane, Figure 1c). The following two advantages are noted for the (diethynylbenzene)diyl diruthenium complexes with the Ru-C $\equiv \mathrm{C}-p-\mathrm{C}_{6} \mathrm{H}_{4}-\mathrm{C} \equiv \mathrm{C}-\mathrm{Ru}$ core skeletons: (1) the 1e-oxidized monocationic species can be stabilized by the diruthenium structures due to the formation of stable MV states and (2) the electronic properties of the neutral and monocationic species can be finely modulated by substituents on the central phenylene moiety. ${ }^{23}$

\section{RESULTS AND DISCUSSION}

Synthesis and Characterization of Neutral Complexes $\mathbf{1}^{\mathbf{R}}$. We have synthesized the diruthenium acetylide complexes $\mathbf{1}^{\mathbf{R}}\left(\mathrm{R}=\mathrm{OMe}, \mathrm{H}, \mathrm{CF}_{3}\right)$ through coupling between the mononuclear chloro precursor with the SMe-terminated acetylide ligand and appropriate 2,5-disubstituted 1,4diethynylbenzenes in 30-72 \% yields in a manner similar to the method reported previously. ${ }^{24-26}$ The obtained diruthenium complexes $\mathbf{1}^{\mathbf{R}}$ were fully characterized through conventional spectroscopic methods including nuclear magnetic resonance (NMR), infrared and high-resolution mass spectroscopy, and elemental analyses. Single sets of ${ }^{1} \mathrm{H}$ (Figure $\left.2 \mathrm{~b}\right)$ and ${ }^{31} \mathrm{P}\left\{{ }^{1} \mathrm{H}\right\}$ NMR signals $\left(\delta_{\mathrm{p}} \sim 54 \mathrm{ppm}\right.$, See SI) indicate highly symmetric structures. $v(C \equiv C)$ vibration frequencies observed around $2060 \mathrm{~cm}^{-1}$ are comparable to those of the relevant ruthenium acetylides. ${ }^{24,25}$ The X-ray structure of $\mathbf{1}^{\mathbf{H}}$ shown in Figure $2 \mathrm{c}$ reveals a rigid rod-like structure, and the $\mathrm{Ru}-\mathrm{Ru}$ and S-S distances were 12.190 and $30.819 \AA$, respectively. The Ru-C $(2.040 \AA)$ and $\mathrm{C} \equiv \mathrm{C}$ $(1.219 \AA$ ) bond lengths are within the ranges of those reported previously. ${ }^{25}$

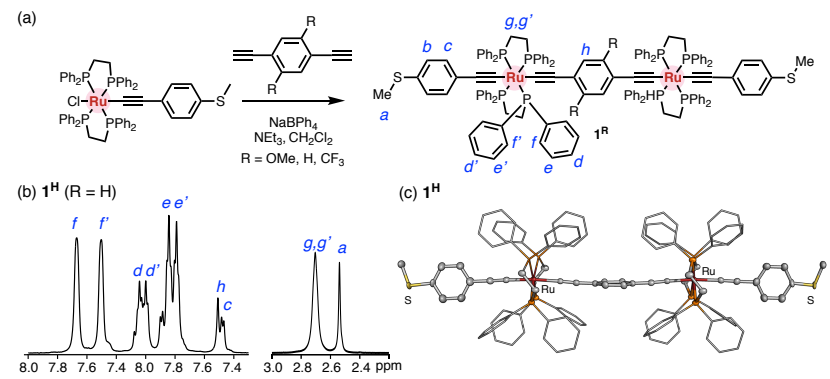

Figure 2. (a) Synthesis of $\mathbf{1}^{\mathbf{R}}\left(\mathrm{R}=\mathrm{OMe}, \mathrm{H}, \mathrm{CF}_{3}\right)$. (b) A ${ }^{1} \mathrm{H} N \mathrm{NR}$ spectrum of $\mathbf{1}^{\mathrm{H}}$ observed at $500 \mathrm{MHz}$ in $\mathrm{CDCl}_{3}$ at r.t. (c) The Xray structure of $\mathbf{1}^{\mathrm{H}}$ with a thermal ellipsoid plot of $50 \%$ probability. Phenyl rings in the dppe ligands are drawn with a wire model.

\section{Preparation and Characterization of Monocationic Species [1 $\left.{ }^{\mathrm{R}}\right][\mathrm{BARF}]$.}

To investigate the electrochemical properties of $\mathbf{1}^{\mathrm{R}}(\mathrm{R}=$ $\mathrm{OMe}, \mathrm{H}, \mathrm{CF}_{3}$ ), cyclic voltammetry was performed. All the three complexes $\mathbf{1}^{\mathbf{R}}$ exhibited two reversible wellseparated oxidation waves in the range from 0 to $-500 \mathrm{mV}$ (vs. $\mathrm{FeCp}_{2} / \mathrm{FeCp}_{2}{ }^{+}$redox couple, Figure $3 \mathrm{a}$ ). On the basis of the separation of the two redox waves $(\Delta E)$, the comproportionation constants $\left(K_{\mathrm{C}}\right)$ were determined to be $7.8 \mathrm{x}$ $10^{3}\left(\mathbf{1}^{\mathrm{CF} 3}\right), 1.4 \times 10^{5}\left(\mathbf{1}^{\mathrm{H}}\right)$, and $1.8 \times 10^{6}\left(\mathbf{1}^{\mathrm{OMe}}\right)$. The large $K_{\mathrm{C}}$ values and the reversible redox waves indicate formation of the monocationic species $\left[\mathbf{1}^{\mathrm{R}}\right]^{+}$thermodynamically stable in solutions.

Monocationic species [ $\left.\mathbf{1}^{\mathrm{R}}\right][\mathrm{BARF}]\left(\mathrm{R}=\mathrm{H}\right.$ and $\mathrm{OMe}$; $\mathrm{BARF}^{-}$ $\left.=\mathrm{B}^{-}\left(3,5-\left(\mathrm{CF}_{3}\right)_{2} \mathrm{C}_{6} \mathrm{H}_{3}\right)_{4}\right)$ were synthesized by treatment of $\mathbf{1}^{\mathrm{R}}$ dissolved in $\mathrm{CH}_{2} \mathrm{Cl}_{2}$ with 1 eq. of [ $\mathrm{FeCp}_{2}$ ] [BARF], and were 
(a)
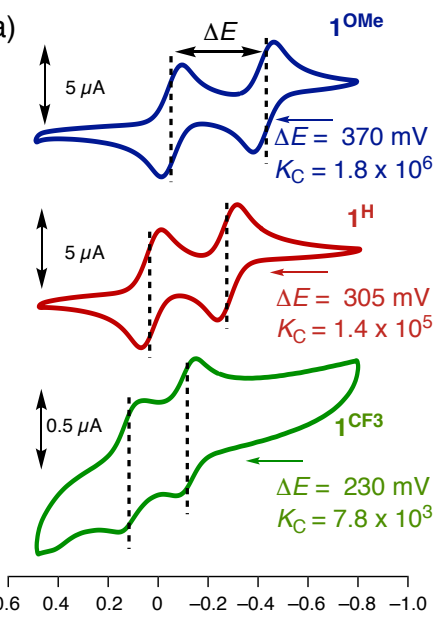
Potential / V vs. Fc/Fc ${ }^{+}$

(c)

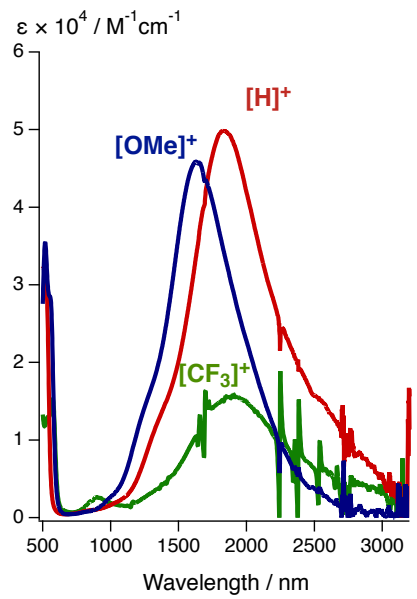

(b)
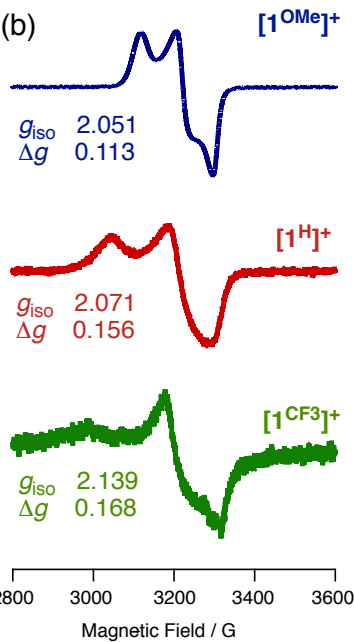

(e)

$\left[1^{\mathrm{OMe}}\right]^{+}$
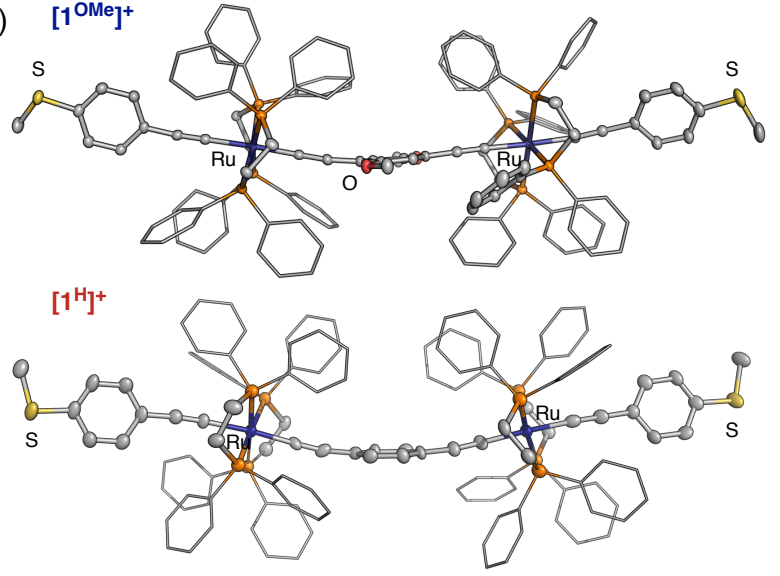
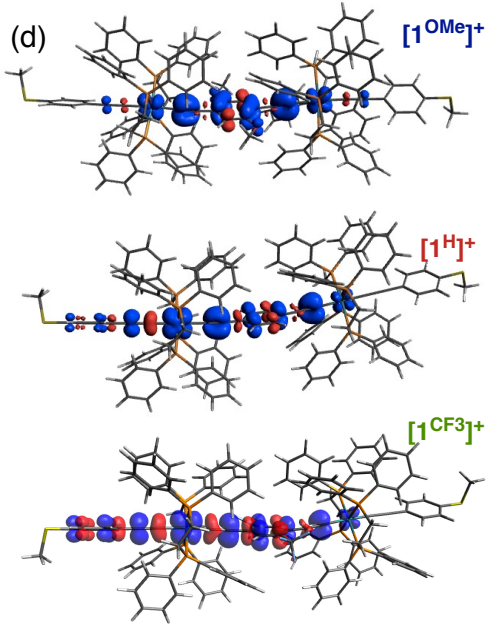

Figure 3. Physicochemical data for $\mathbf{1}^{\mathbf{R}}$. (a) Cyclic voltammograms: $\mathbf{1}^{\mathbf{H}}$ and $\mathbf{1}$ oMe: $1.0 \mathrm{mM}$ in $\mathrm{CH}_{2} \mathrm{Cl}_{2} ; \mathbf{1}^{\mathbf{C F} 3:} 0.1 \mathrm{mM}$ in $\mathrm{CH}_{2} \mathrm{Cl}_{2}(0.1 \mathrm{mM}$ $\left[n-\mathrm{Bu}_{4} \mathrm{~N}\right]\left[\mathrm{PF}_{6}\right]$, W.E and C.E : Pt, R.E : Ag/ Ag+, r.t.). (b) ESR spectra (113 K in $\mathrm{CH}_{2} \mathrm{Cl}_{2}$ glasses). (c) Vis-NIR spectra of [1R]+ (0.1 mM in $\mathrm{CH}_{2} \mathrm{Cl}_{2}$ ). (d) Spin density plots obtained by the DFT calculations (BLYP35-D3/Def2SVP,PCM $\left(\mathrm{CH}_{2} \mathrm{Cl}_{2}\right)$ ). (e) X-ray structures of the cationic parts of $\left[\mathbf{1 0 M e}^{+}\right.$and $\left[\mathbf{1}^{\mathrm{H}}\right]^{+}$. Hydrogen atoms and solvents' molecules were omitted. Phenyl rings in the dppe ligands are depicted as the wire models.

isolated in $64\left(\left[\mathbf{1}^{\mathrm{H}}\right][\mathrm{BARF}]\right)$ and $95 \%$ isolated yields ([10Me $][\mathrm{BARF}])$. Although our attempts to isolate $\left[\mathbf{1}^{\mathrm{CF}}\right][\mathrm{BARF}]$ have not been successful yet probably due to its smaller $K_{C}$ value, the monocationic species $\left[\mathbf{1}^{\mathbf{C F} 3}\right]^{+}$ turned out to be stable in solution under ambient conditions (vide supra) and thus in the following measurements, $\left[\mathbf{1}^{\mathbf{C F} 3}\right]^{+}$was generated in situ by the treatment of $\mathbf{1}^{\mathbf{C F} 3}$ with 1 eq. of [ $\left.\mathrm{FeCp}_{2}\right][\mathrm{BARF}]$.

The monocationic species $\left.\mathbf{1}^{\mathrm{R}}\right][\mathrm{BARF}]$ were readily characterized by electron spin resonance (ESR) and near infrared (NIR) absorption spectroscopy (Figure 3b). ESR spectra of $\left[\mathbf{1}^{\mathrm{R}}\right][\mathrm{BARF}]$ observed at $113 \mathrm{~K}$ as $\mathrm{CH}_{2} \mathrm{Cl}_{2}$ glasses revealed rhombic signals typical of the $\mathrm{Ru}(\mathrm{dppe})_{2}$ complexes with an unpaired spin. The isotropic parameters $\left(g_{\text {iso }}=\left(g_{1}\right.\right.$ $\left.+g_{2}+g_{3}\right) / 3 ;\left[\mathbf{1 0 M e}^{\mathrm{OM}}+2.051 ;\left[\mathbf{1}^{\mathrm{H}}\right]+2.071 ;\left[\mathbf{1}^{\mathbf{C F} 3}\right]+2.139\right)$ are close to that for the free organic radical $\left(g_{\text {free }}=2.0023\right)$, and the split parameters $(\Delta g)$ decrease with the electrondonating substituents $\left(\left[\mathbf{1}^{\mathbf{\text { Me}}}\right]^{+} 2.051 ;\left[\mathbf{1}^{\mathbf{H}}\right]^{+} 2.071 ;\left[\mathbf{1}^{\mathbf{C F} 3}\right]^{+}\right.$ 2.139), suggesting that the 1e-oxidized cationic radical $\left[\mathbf{1 0 M e}^{+}\right.$bears more contribution of the organic parts. In- tense NIR absorptions observed for [1 $\left.\mathbf{1}^{\mathrm{R}}\right]$ [BARF] $\left(\lambda_{\max }=\right.$ $\left.1656\left(\left[\mathbf{1}^{\text {(Me }}\right]^{+}\right), 1825\left(\left[\mathbf{1}^{\mathbf{H}}\right]^{+}\right), 1903 \mathrm{~nm}\left(\left[\mathbf{1}^{\mathrm{CF} 3}\right]^{+}\right)\right)$should stem from the intramolecular $\mathrm{Ru}-\mathrm{Ru}$ interaction in $\left[\mathbf{1}^{\mathrm{R}}\right]^{+}$ (Figure 3c). The absorptions disappear upon addition of excess amounts of $\left[\mathrm{FeCp}_{2}\right][\mathrm{BARF}]$ due to formation of the corresponding dicationic species $\left[\mathbf{1}^{\mathrm{R}}\right]^{2+}$ (Figure S10).

The spin density distributions estimated by the DFT study reveal even distribution on the two $\mathrm{Ru}$ atoms for $\left[\mathbf{1}^{\mathbf{0 M e}}\right]^{+}$ $(0.15: 0.15)$ and uneven distribution for $\left[\mathbf{1}^{\mathrm{H}}\right]^{+}(0.47: 0.05)$ and $\left[\mathbf{1}^{\mathbf{C F} 3}\right]^{+}(0.42: 0.06$, Figure $3 \mathrm{~d})$. Thus, complexes $\left[\mathbf{1}^{\mathbf{H}}\right]^{+}$ and $\left[\mathbf{1}^{\mathbf{C F} 3}\right]^{+}$are classified into charge-localized class II compounds, while the OMe derivative $\left[\mathbf{1 0 M e}^{+}\right.$is a chargedelocalized class III compound.

Solid-state structures of $\left[\mathbf{1}^{\mathbf{H}}\right][\mathrm{BARF}]$ and $\left[\mathbf{1}^{\mathrm{OMe}}\right][\mathrm{BARF}]$ were characterized by X-ray diffraction study (Figure 3e). The diethynylbenzene moieties slightly distorted from the planarity $\left(\angle \mathrm{C}_{\mathrm{Ar}}-\mathrm{C} \equiv \mathrm{C}=168.5^{\circ}\right)$. Compared to the neutral compound $\mathbf{1}^{\mathbf{H}}$, the bonding features change from the acetylene structure $\mathrm{Ru}-\mathrm{C} \equiv \mathrm{C}-\mathrm{C}_{\mathrm{Ar}}$ to the cumulenic structure $\mathrm{Ru}=\mathrm{C}=\mathrm{C}=\mathrm{C}_{\mathrm{Ar}}$ as indicated by the shortening of the $\mathrm{Ru}-\mathrm{C}$ 
$(2.033 \AA)$ and $\equiv \mathrm{C}-\mathrm{C}_{\mathrm{Ar}}$ bonds $(1.425 \AA)$ as well as the lengthening of the $\mathrm{C} \equiv \mathrm{C}$ bonds $\left(d_{\mathrm{C} \equiv \mathrm{Cav}}=1.217 \AA\right.$ ) (cf. $\mathbf{1}^{\mathrm{H}}: d_{\mathrm{Ru}}$ Cav $(2.050 \AA$ ) $\left.), d_{\equiv C \text {-CArav }}(1.446 \AA), d_{\mathrm{C} \equiv \text { Cav }}(1.223 \AA)\right)$ ). In accord with the Robin-Day classification discussed above, the unsymmetrical bonding feature of the $\mathrm{Ru}-\mathrm{C} \equiv \mathrm{C}-\mathrm{Ar}-\mathrm{C} \equiv \mathrm{C}-\mathrm{Ru}$ moiety in $\left[\mathbf{1}^{\mathrm{H}}\right]^{+}$is in contrast to the virtually symmetrical feature in [ $\left.\mathbf{1}^{\mathbf{O M e}}\right]^{+}$(Tables S2, 3). This is also supported by the DFT study.
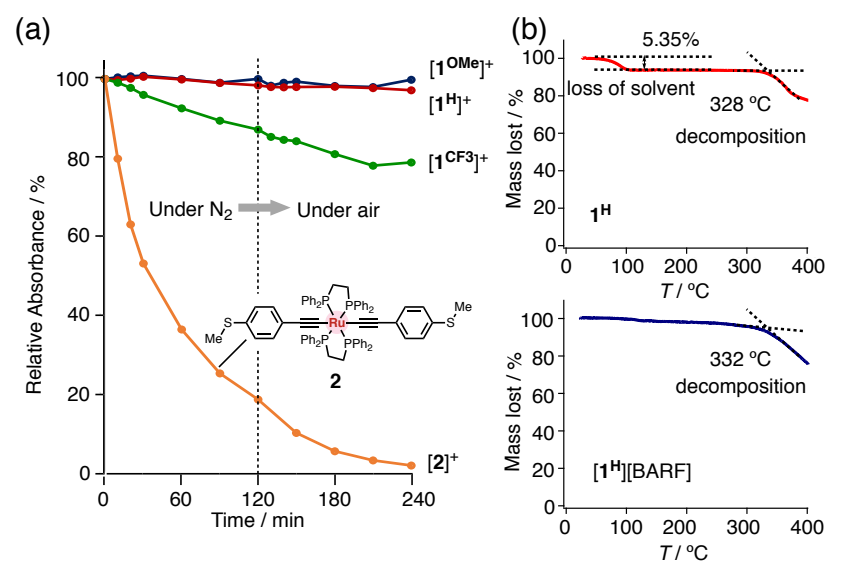

Figure 4. (a) Time-course plots of the Vis-NIR absorptions of $\left[\mathbf{1}^{\mathrm{R}}\right][\mathrm{BARF}]\left(\mathrm{R}=\mathrm{OMe}, \mathrm{H}, \mathrm{CF}_{3}\right)$ in $\mathrm{CH}_{2} \mathrm{Cl}_{2}([$ complex $]=0.1 \mathrm{mM})$. The experiments were performed under nitrogen atmosphere (from 0 to $120 \mathrm{~min}$ ) and then the solutions were exposed to air. (b) TG thermograms of $\mathbf{1}^{\mathbf{H}}$ and [ $\mathbf{1}^{\mathbf{H}}$ ][BARF]. The amount of the lost $\mathrm{CH}_{2} \mathrm{Cl}_{2}$ solvent for $\mathbf{1}^{\mathrm{H}}$ was in good agreement with the E.A data.

\section{Stability and Reversibility of Switching Behavior.}

High thermal stability of $\left[\mathbf{1}^{\mathbf{R}}\right]^{+}$under ambient conditions is highlighted by the time-course analysis of the Vis-NIR absorptions of [ $\left.\mathbf{1}^{\mathrm{R}}\right][\mathrm{BARF}]$ dissolved in $\mathrm{CH}_{2} \mathrm{Cl}_{2}$. The dinuclear complexes [ $\left.\mathbf{1}^{\mathrm{R}}\right]$ [BARF] turned out to be stable for $2 \mathrm{~h}$ both under nitrogen atmosphere and in air as can be seen from the retention of the Vis-NIR absorptions (10Me $100 \% ; \mathbf{1}^{\mathbf{H}}$ 98\%; 1 163 79\%), whereas the mononuclear analogue 2 rapidly and almost completely decomposed under the same conditions (Figure 4a). These results proved that the dinuclear skeleton is one of effective methods to stabilize monocationic radical species containing the $\mathrm{Ru}(\mathrm{dppe})_{2}$ fragment. Because the sequential treatment of $\mathbf{1}^{\mathrm{H}}$ with [FeCp 2 [BARF] and $\mathrm{FeCp}_{2}{ }_{2}$ to $\mathbf{1}^{\mathbf{H}}$ caused reversible Vis-NIR spectral changes (Figure S11), the redox process can be repeated at least 6 times in solution.

Furthermore, thermogravimetric analysis of the neutral $\mathbf{1}^{\mathbf{H}}$ and cationic $\left[\mathbf{1}^{\mathrm{H}}\right][\mathrm{BARF}]$ complexes revealed that they were stable up to around $300^{\circ} \mathrm{C}$ (Figure $4 \mathrm{~b}$ ). This high thermal stability in the solid-state should benefit device fabrication and switching operation in the nanogap.

STM-BJ Study. Using the STM-break junction (BJ) technique, ${ }^{27}$ we measured single-molecule conductance of $\mathbf{1}^{\mathrm{R}}$ and $\left[\mathbf{1}^{\mathrm{R}}\right][\mathrm{BARF}]$ in mesitylene (Figure $5 \mathrm{a}-\mathrm{c}$ ). The $1 \mathrm{D}$ histograms of both of the neutral and monocationic species reveal the conductance features in the range of $10^{-2}-10^{-6} G_{0}$. The statistical analyses give the single-molecule conductance of the neutral and monocationic species as summarized in Table 1, and the conductance plot against the Hammett parameter $\sigma^{28}$ is shown in Figure 5d. The fea- tures of the 2D histograms extended over $2.5 \mathrm{~nm}$ are consistent with the connection of $\left[\mathbf{1}^{\mathrm{R}}\right]^{n+}$ at the terminal thiomethyl anchor groups $\left(d_{\mathrm{s} \cdots \mathrm{s}} \sim 3.0 \mathrm{~nm}\right)$ when the snapback distance $(\sim 0.5 \mathrm{~nm})$ are taken into account (Figures $5 \mathrm{e}, \mathrm{f}$, and S17a). The conductance of the neutral species increases by introduction of the electron-donating substituents (225-fold from $\mathbf{1}^{\text {CF3 }}$ to $\mathbf{1}^{\mathbf{O M e}}$ ). Compared with molecular junctions composed of simple organic molecules such as phenylenediamine ${ }^{29}$ and carbazole derivatives, ${ }^{30}$ the large conductance change of $\mathbf{1}^{\mathbf{R}}$ induced by the substituents is remarkable. On the other hand, conductance of the monocationic species follows the opposite trend, i.e. conductance decrease from $\left[\mathbf{1}^{\mathrm{CF} 3}\right]^{+}$to $\left[\mathbf{1}^{\mathrm{OMe}}\right]^{+}$by 0.4 -fold. As a result, the $\mathrm{ON} / \mathrm{OFF}$ switching ratio, which is relative ratio of the conductance of the monocationic species in relation to the neutral ones, drastically changes from 191 (for the $\mathrm{CF}_{3}$ derivatives) to 48 (for the $\mathrm{H}$ derivatives) and then to 0.4 (for the OMe derivatives). This result shows that the organometallic molecular switch $\mathbf{1}^{\mathbf{R}_{-}}\left[\mathbf{1}^{\mathrm{R}}\right]^{+}$can be facilely and effectively modulated by the substituents on the central aromatic rings.

We also carried out in situ switching experiments (Figure 5g). Addition of an equimolar amount of [FeCp 2$][B A R F]$ to a mesitylene solution of $\mathbf{1}^{\mathbf{H}}$ caused a shift of the conductance peak to $10^{-3} G_{0}$ suggestive of generation of $\left[\mathbf{1}^{\mathbf{H}}\right]^{+}$. Inversely, in-situ reduction of a mesitylene solution of $\left[\mathbf{1}^{\mathbf{H}}\right][\mathrm{BARF}]$ by $\mathrm{FeCp}_{2}{ }_{2} \quad\left(\mathrm{Cp}^{*} ; 1,2,3,4,5-\right.$ pentamethylcyclopentadienyl) led to replacement of the conductance peak of [ $\left.\mathbf{1}^{\mathrm{H}}\right][\mathrm{BARF}]$ with that around $10^{-5} \mathrm{G}_{0}$, which was superimposable on that of $\mathbf{1}^{\mathrm{H}}$. Thus, the switching behavior could be reproduced reversibly in solution.

DFT-NEGF study. To gain insight into the tunable ON/OFF ratios, we carried out DFT-NEGF calculations on molecular junction models of $\left[\mathbf{1}^{\mathbf{R}^{\prime}}\right]^{n+}(n=0,1)$ with truncated bis(dimethylphosphino)methane ligands with the Au clusters attached to the terminal thiomethyl groups (Figure 5h, i). ${ }^{31-33}$ The HOMO transmission peaks of the neutral species are located close to the Fermi energy level $\left(E_{\mathrm{F}}\right)$ and are sensitive to the substituents. The HOMO transmission peaks approach to $E_{\mathrm{F}}$, as the substituents become more electron-donating $\left(\mathrm{CF}_{3}(-0.23 \mathrm{eV}) \rightarrow \mathrm{H}(-0.10 \mathrm{eV}) \rightarrow \mathrm{OMe}\right.$ $(-0.03 \mathrm{eV})$; highlighted as the square marks in Figure $4 \mathrm{~h})$ as is also supported by the HOMO energies estimated from the cyclic voltammograms $\left(\mathrm{CF}_{3}(-4.93 \mathrm{eV}) \rightarrow \mathrm{H}(-4.76 \mathrm{eV})\right.$ $\rightarrow$ OMe $(-4.61 \mathrm{eV}))$. Theoretically estimated conductance of $\mathbf{1}^{\mathbf{O M e}}$ ' significantly increases compared to those of $\mathbf{1}^{\mathbf{H}^{\prime}}$ and

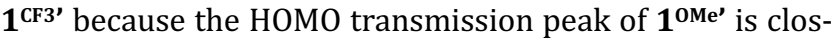
er to the Fermi level. Because slope of the transmission spectrum at $E_{\mathrm{F}}$ is steep, a small shift of the transmission peak energy leads to a large conductance change. By contrast, the HOMO-LUMO gaps of simple organic molecules are, in general, so large that the conduction peaks are located far apart from the Fermi level. As a result, the conductance around $E_{\mathrm{F}}$ becomes small to make the transmission curve around $E_{\mathrm{F}}$ flat and lead to the less sensitivity of the conduction to the substituents. 

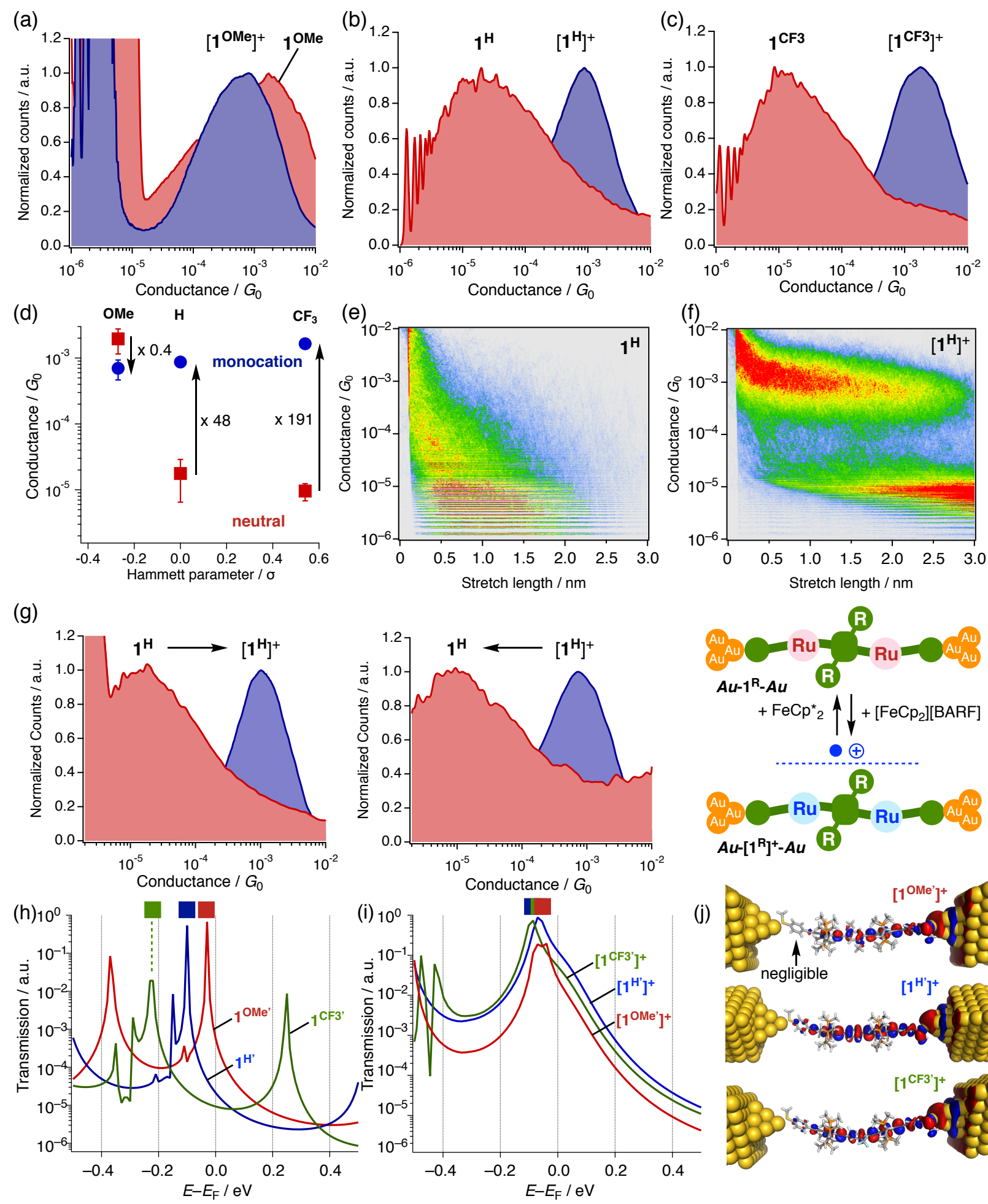

(j)
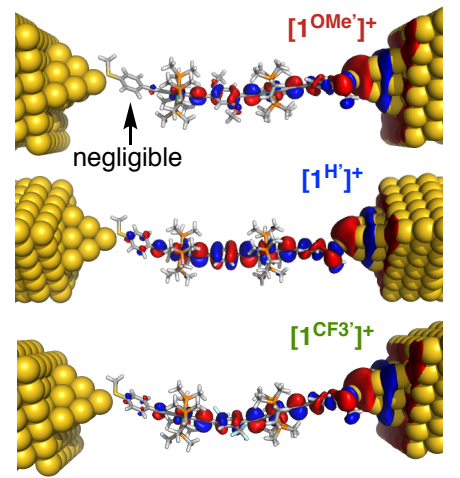

Figure 5. 1D histograms obtained by the STM-BJ study of (a) $\left[\mathbf{1}^{\mathbf{O M e}}\right]^{n+},(\mathrm{b})\left[\mathbf{1}^{\mathrm{H}}\right]^{n+}$ and $(\mathrm{c})\left[\mathbf{1} \mathbf{1 F}^{\mathrm{CF}}\right]^{n+}(n=0,1)$. (d) Plots of conductance versus Hammett parameter. (e,f) 2D histograms of $\mathbf{1}^{\mathbf{H}}$ and [1 $\mathbf{1}$ ] [BARF]. (g) In situ oxidation of $\mathbf{1}^{\mathrm{H}}$ with [FeCp ${ }_{2}$ [BARF] and reduction

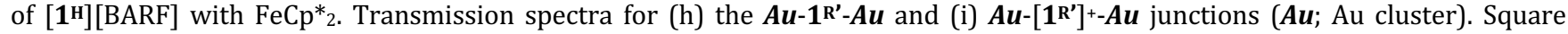

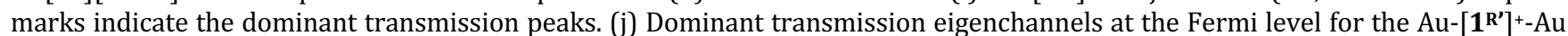
junctions. 
Table 1. Experimental and theoretical conductance of $\mathbf{1}^{\mathbf{R}}$ and $\left[\mathbf{1}^{\mathrm{R}}\right]^{+}$.

\begin{tabular}{|c|c|c|c|c|c|}
\hline \multicolumn{4}{|c|}{ Experiment } & \multicolumn{2}{|c|}{ DFT-NEGF } \\
\hline & \multicolumn{2}{|c|}{ conductance $/ \times 10^{-5} G_{0}$} & \multirow[t]{2}{*}{ ON/OFF ratio } & \multicolumn{2}{|c|}{ conductance $/ \times 10^{-5} G_{0}$} \\
\hline $\begin{array}{c}\mathrm{R} \text { in } \mathbf{1}^{\mathbf{R}} \\
\text { and }\left[\mathbf{1}^{\mathbf{R}}\right]^{+}\end{array}$ & neutral $\left(\mathbf{1}^{\mathbf{R}}\right)$ & $\begin{array}{c}\text { monocation } \\
\left(\left[\mathbf{1}^{\mathbf{R}}\right][\text { BARF }]\right)\end{array}$ & & neutral $\left(\mathbf{1}^{\mathbf{R}}\right)$ & monocation $\left(\left[\mathbf{1}^{\mathbf{R}}\right]^{+}\right)$ \\
\hline $\mathrm{OMe}$ & $200( \pm 80)$ & $71( \pm 44)$ & 0.35 & 57 & 2050 \\
\hline $\mathrm{H}$ & $1.8( \pm 1.1)$ & $87( \pm 11)$ & 48 & 2.2 & 10700 \\
\hline $\mathrm{CF}_{3}$ & $0.89( \pm 0.28)$ & $170( \pm 20)$ & 191 & 0.96 & 4500 \\
\hline
\end{tabular}

On the other hand, the energy levels of the transmission peaks of the monocationic species $\left[\mathbf{1}^{\mathbf{R}^{\prime}}\right]^{+}$are in the very narrow range irrespective of $\mathrm{R}$ (Figure 5i). This phenomenon can be interpreted in terms of the pinning effect, i.e. the singly occupied orbital of open-shell species is placed at the energy level close to the Fermi energy. As a result, molecular junctions reveal conductance almost identical regardless of the molecular backbone. ${ }^{34}$ However, the BJ study of the monocationic species revealed slight decrease of conductance by introduction of the OMe substituents (0.4-fold from $\left[\mathbf{1}^{\mathrm{CF} 3}\right]^{+}$to $\left.\left[\mathbf{1}^{\mathrm{OMe}}\right]^{+}\right)$. The trend is also suggested by the calculations; the conductance peak of $\left[\mathbf{1}^{\mathbf{0 M e}}\right]^{+}$is weaker than those of $\left[\mathbf{1}^{\mathbf{H}^{\prime}}\right]^{+}$and $\left[\mathbf{1}^{\mathrm{CF}}{ }^{\prime}\right]^{+}$. According to the transmission eigenchannels (Figure 5j), the contribution of one of the two terminal anchor groups of $\left[\mathbf{1}^{\mathbf{0 M e}}\right]^{+}$(indicated with the arrow) is smaller than those of $\left[\mathbf{1}^{\mathrm{H}^{\prime}}\right]^{+}$and $\left[\mathbf{1}^{\mathrm{CF}^{\prime}}\right]^{+}$, suggesting that the weak electronic coupling between the molecule and the electrode.

Considering the Marcus-Hush regime, the fact that the $M V$ complexes shows similar conductance regardless of the charge-delocalized states is against our expectation. ${ }^{35-37}$ Highly charge-delocalized class III systems are expected to show high carrier mobility, while class II systems should show lower carrier mobility in solution and bulk solid state as well. However, our results suggest that, in the singlemolecule conductance, there is no apparent relationship between charge-delocalization and conductance, and even the trend is inversed i.e. the class II systems $\left(\left[\mathbf{1}^{\mathrm{H}}\right]^{+}\right.$and $\left.\left[\mathbf{1}^{\mathrm{CF} 3}\right]^{+}\right)$exhibit conductance higher than the Class III system $\left(\left[\mathbf{1}^{\mathrm{OMe}}\right]^{+}\right)$. This discrepancy can be interpreted as follows: in the coherent tunneling process, interaction between the metal electrodes and the molecule dominates the conductance (pinning effect) rather than the intramolecular interaction. By contrast, the Marcus-Hush-type charge transfer phenomena deal with thermal activation processes accompanying solvent reorganization. Thus, significant MV character in molecular junction may appear when the conductance mechanism is dominated by thermally activated hopping process. ${ }^{38}$

\section{Switching behavior in Nano-gap.}

The switching function of the $\mathbf{1}^{\mathrm{R}} /\left[\mathbf{1}^{\mathrm{R}}\right]^{+}$system was further studied by the nanogap technique. The conductance obtained by the STM-BJ technique is not for a specific molecule because after the break junction step another molecule comes into the electrodes and the process is repeated many times. So we can just obtain averaged features of molecules in the sample solution. In contrast to the dynamic STM-BJ technique, the static nanogap technique described below does not involve such BJ steps and molecules sandwiched between the nanogap stay there during the measurement so that we can observe changes of a particular molecules fixed between the electrodes. Therefore, we have chances to observe the switching process of fixed molecules induced by in-situ redox processes.

The $1 \mathrm{~nm}$-sized nanogap NGO was prepared following the procedure reported previously. ${ }^{39}$ The $I-V$ characteristic of $\mathbf{N G s}$ obtained after immersion in $\mathbf{1}^{\mathbf{H}}\left(\mathbf{N G} \mathbf{1}^{\mathbf{H}}\right)$ or $\left[\mathbf{1}^{\mathbf{H}}\right]\left[\mathrm{PF}_{6}\right]$ solution $\left(\mathbf{N G}\left[\mathbf{1}^{\mathrm{H}}\right]^{+}\right)$revealed resistance of $7.96 \mathrm{G} \Omega\left(\mathbf{N G}^{\mathrm{H}}\right)$ and $1.61 \mathrm{G} \Omega\left(\mathbf{N G}\left[\mathbf{1}^{\mathrm{H}}\right]^{+}\right)$at $0.1 \mathrm{~V}$, which were significantly smaller than the value obtained with a bare nanogap NG0 (546 G $\Omega)^{40}$ Furthermore, we performed surface enhanced Raman scattering (SERS) experiments of NG1 ${ }^{\mathbf{H}}$ to confirm molecular finger print in the nanogap.41-44 The Raman spectrum obtained from $\mathbf{N G 1} \mathbf{H}^{\mathrm{H}}$ showed characteristic signals at $520,1000,1070$, and $1175 \mathrm{~cm}^{-1}$, which correspond to those observed for the bulk sample of $\mathbf{1}^{\mathrm{H}}$ as compared in Figure 6b. The Raman mapping images provided high Raman intensity points at the nanogap (Figure 6b inset), supporting the molecular junction formation.

In situ ON/OFF experiment was performed for the nanogap containing $\mathbf{1}^{\mathrm{R}}$ described above (NG1 $\left.{ }^{\mathrm{H}}\right)$. Immersion of $\mathbf{N G 1}^{\mathbf{H}}$ in a $\mathrm{CH}_{2} \mathrm{Cl}_{2}$ solution of [ $\left.\mathrm{FeCp}_{2}\right][\mathrm{BARF}$ ) gave $\mathbf{N G}\left[\mathbf{1}^{\mathbf{H}}\right]^{+}$, which showed the conductance increased by a factor of 42 (at 1V). This change should correspond to the formation of the nanogap containing $\left[\mathbf{1}^{\mathrm{H}}\right]^{+}$-bridges. Recovery of the conductance was achieved by further treatment of $\mathbf{N G}\left[\mathbf{1}^{\mathbf{H}}\right]^{+}$with a mesitylene solution of $\mathrm{FeCp}^{*}$. Thus, this study demonstrated the ON/OFF switching behavior of the dinuclear molecular switch and its potential application for molecular devices. 


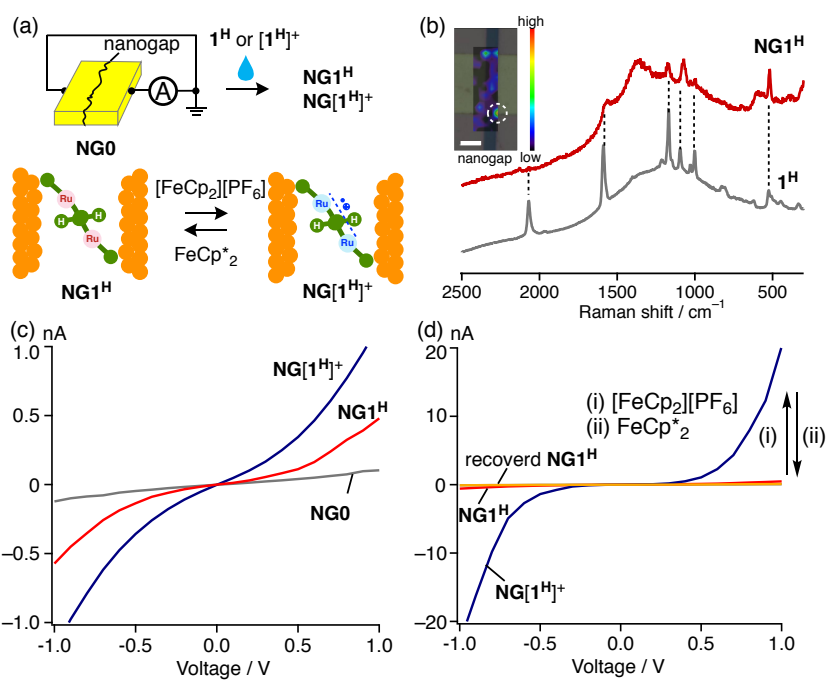

Figure 6. (a) Schematic images of preparation of nanogap junctions $\mathbf{N G 1}^{\mathbf{H}}$ and $\mathbf{N G}\left[\mathbf{1}^{\mathrm{H}}\right]^{+}$, and in situ oxidation and reduc-

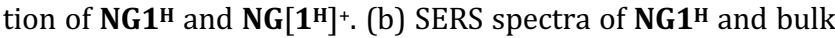
samples of $\mathbf{1}^{\mathrm{H}}$. The inset shows a Raman mapping image of NG1H. The high Raman intensity point (highlighted by a circle) was observed in the nanogap. ${ }^{45}$ The white scale bar indicates $10 \mu \mathrm{m}$. (c) $I-V$ curves of NG0, NG1H and NG[1 $\left.\mathbf{1}^{\mathbf{H}}\right]^{+}$. (d) In situ $\mathrm{ON} / \mathrm{OFF}$ switching experiments of $\mathbf{N G 1}^{\mathrm{H}}$ with sequential addition of $\left[\mathrm{FeCp}_{2}\right]\left[\mathrm{PF}_{6}\right]$ and $\mathrm{FeCp}_{2}$.

\section{CONCLUSION}

In summary, we have developed new organometallic molecular switches $\mathbf{1}^{\mathbf{R}}\left[\mathbf{1}^{\mathbf{R}}\right]^{+}$responding to redox stimuli. Both of the neutral and monocationic MV complexes are stable under ambient conditions (at r.t. in air). It is notable that the monocationic species, otherwise usually unstable (in particular, mononuclear systems), are stabilized by the $d \pi$ systems delocalized widely over the $\mathrm{Ru}-\mathrm{C} \equiv \mathrm{C}-\mathrm{Ar}-\mathrm{C} \equiv \mathrm{C}-\mathrm{Ru}$ linkages to lead to the stable MV states. Single-molecule conductance study reveals that the molecules show switching behavior. Interestingly, the ON/OFF switching ratio can be facilely controlled by the substituents embedded into the bridging linkers up to a factor of $c a$. 200, mainly due to a drastic conductance change of the neutral species. This change is responsible for the high-lying HOMO orbitals caused by the electron-rich ruthenium fragments. We have also demonstrated the switching behavior in the nanogap, which shows potential application to device fabrication. Notably, this study presents a rare example of a singlemolecule conductance study of the MV complexes, ${ }^{46,47}$ and achievement of tunable ON/OFF ratio. Thus, we have revealed that the dinuclear organometallic system offers a new platform for a modulable molecular switch, which will open new molecular electronic fields.

\section{AUTHOR INFORMATION}

\section{Corresponding Authors}

Yuya Tanaka -

orcid.org/0000-0002-0674-660X; Email:

ytanaka@res.titech.ac.jp

Munetaka Akita -

orcid.org/ 0000-0001-7007-9621; Email: akitatit@icloud.com

\section{Author Contributions}

YT and MA conceived the project. NM carried out all the experiments and NM and YT analyzed data. YT, TO and HT contributed the theoretical study. SK measured SERS spectra. NM and YN performed nano-gap experiments. SF and TN supervised STM-BJ experiments. The manuscript was drafted by YT and edited by MA. All authors read and approved the final manuscript.

\section{Author Information Notes}

$\dagger$ These authors contributed equally to this work.

\section{Funding Sources}

JSPS KAKENHI Grant Numbers (18K05139 and 21K05211)

JST, PRESTO Grant Number JPMJPR2115

ENEOS Tonengeneral Research/Development Encouragement \& Scholarship Foundation

The Asahi Glass Foundation

Inamori Foundation

Tokyo Kasei Chemical Promotion foundation

Tokuyama Science Foundation.

Notes

The authors declare no competing financial interest.

\section{ACKNOWLEDGMENT}

We gratefully thank Prof. Hideyuki Otsuka and Mr. Takumi Yamamoto (Tokyo Tech) for their kind help in measuring EPR spectroscopy. The theoretical calculations were performed by using computers in Research Center for Computational Science, Okazaki, Japan.

\section{REFERENCES}

(1) Kiguchi, M.; Ohto, T.; Fujii, S.; Sugiyasu, K.; Nakajima, S.; Takeuchi, M.; Nakamura, H. Single Molecular Resistive Switch Obtained via Sliding Multiple Anchoring Points and Varying Effective Wire Length. J. Am. Chem. Soc. 2014, 136 (20), 7327-7332. https://doi.org/10.1021/ja413104g.

(2) Pei, L.-Q.; Horsley, J. R.; Seng, J.-W.; Liu, X.; Yeoh, Y. Q.; Yu, M.-X.; Wu, X.-H.; Abell, A. D.; Zheng, J.-F.; Zhou, X.-S.; Yu, J.; Jin, S. Mechanically Induced Switching between Two Discrete Conductance States: A Potential Single-Molecule Variable Resistor. ACS Appl. Mater. Interfaces 2021, 13 (48), 57646-57653. https://doi.org/10.1021/acsami.1c12151.

(3) Li, J.; Shen, P.; Zhen, S.; Tang, C.; Ye, Y.; Zhou, D.; Hong, W.; Zhao, Z.; Tang, B. Z. Mechanical Single-Molecule Potentiometers with Large Switching Factors from Ortho-Pentaphenylene Foldamers. Nat Commun 2021, 12 (1), 167. https://doi.org/10.1038/s41467-020-20311-z.

(4) Li, Z.; Smeu, M.; Afsari, S.; Xing, Y.; Ratner, M. A.; Borguet, E. Single-Molecule Sensing of Environmental PH-an STM Break Junction and NEGF-DFT Approach. Angew. Chem. Int. Ed. 2014, 53 (4), 1098-1102. https://doi.org/10.1002/anie.201308398.

(5) Yoshihara, Y.; Fujii, S.; Higashibayashi, S.; Kiguchi, M.; Nishino, T. Single-Molecule Electric Switching Induced by AcidBase Reaction. Chem. Lett. 2021, 50 (6), 1271-1273. https://doi.org/10.1246/cl.210088. 
(6) Dulić, D.; van der Molen, S. J.; Kudernac, T.; Jonkman, H. T.; de Jong, J. J. D.; Bowden, T. N.; van Esch, J.; Feringa, B. L.; van Wees, B. J. One-Way Optoelectronic Switching of Photochromic Molecules on Gold. Phys. Rev. Lett. 2003, 91 (20), 207402. https://doi.org/10.1103/PhysRevLett.91.207402.

(7) Whalley, A. C.; Steigerwald, M. L.; Guo, X.; Nuckolls, C. Reversible Switching in Molecular Electronic Devices. J. Am. Chem. Soc. 2007, 129 (42), 12590-12591. https://doi.org/10.1021/ja073127y.

(8) Jia, C.; Migliore, A.; Xin, N.; Huang, S.; Wang, J.; Yang, Q.; Wang, S.; Chen, H.; Wang, D.; Feng, B.; Liu, Z.; Zhang, G.; Qu, D.-H.; Tian, H.; Ratner, M. A.; Xu, H. Q.; Nitzan, A.; Guo, X. Covalently Bonded Single-Molecule Junctions with Stable and Reversible Photoswitched Conductivity. Science 2016, 352 (6292), 14431445. https://doi.org/10.1126/science.aaf6298.

(9) Li, Y.; Baghernejad, M.; Qusiy, A.-G.; Zsolt Manrique, D.; Zhang, G.; Hamill, J.; Fu, Y.; Broekmann, P.; Hong, W.; Wandlowski, T.; Zhang, D.; Lambert, C. Three-State Single-Molecule Naphthalenediimide Switch: Integration of a Pendant Redox Unit for Conductance Tuning. Angew. Chem. Int. Ed. 2015, 54 (46), 1358613589. https://doi.org/10.1002/anie.201506458.

(10) Yin, X.; Zang, Y.; Zhu, L.; Low, J. Z.; Liu, Z.-F.; Cui, J.; Neaton, J. B.; Venkataraman, L.; Campos, L. M. A Reversible SingleMolecule Switch Based on Activated Antiaromaticity. Sci. Adv. 3 (10), eaao2615. https://doi.org/10.1126/sciadv.aao2615.

(11) Chen, Y.; Huang, L.; Chen, H.; Chen, Z.; Zhang, H.; Xiao, Z.; Hong, W. Towards Responsive Single-Molecule Device. Chin. J. $\begin{array}{llll}\text { Chem. 2021, } 39 & \text { (2), 421-439. }\end{array}$ https://doi.org/10.1002/cjoc.202000420.

(12) Li, Z.; Li, H.; Chen, S.; Froehlich, T.; Yi, C.; Schönenberger, C.; Calame, M.; Decurtins, S.; Liu, S.-X.; Borguet, E. Regulating a Benzodifuran Single Molecule Redox Switch via Electrochemical Gating and Optimization of Molecule/Electrode Coupling. J. Am. Chem. Soc. 2014, 136 (25), 8867-8870. https://doi.org/10.1021/ja5034606.

(13) Creutz, C.; Taube, H. Direct Approach to Measuring the Franck-Condon Barrier to Electron Transfer between Metal Ions. J. Am. Chem. Soc. 1969, 91 (14), 3988-3989. https://doi.org/10.1021/ja01042a072.

(14) Ren, T. Diruthenium $\sigma$-Alkynyl Compounds: A New Class of Conjugated Organometallics. Organometallics 2005, 24 (21), 4854-4870. https://doi.org/10.1021/om050452q.

(15) Lissel, F.; Schwarz, F.; Blacque, O.; Riel, H.; Lörtscher, E.; Venkatesan, K.; Berke, H. Organometallic Single-Molecule Electronics: Tuning Electron Transport through $\mathrm{X}$ (Diphosphine)2FeC4Fe(Diphosphine)2X Building Blocks by Varying the $\mathrm{Fe}-\mathrm{X}-\mathrm{Au}$ Anchoring Scheme from Coordinative to Covalent. J. Am. Chem. Soc. 2014, 136 (41), 14560-14569. https://doi.org/10.1021/ja507672g.

(16) Tanaka, Y.; Kiguchi, M.; Akita, M. Inorganic and Organometallic Molecular Wires for Single-Molecule Devices. Chem. Eur. $\begin{array}{llll}\text { J. 2017, } & 23 & \text { (20), } & \text { 4741-4749. }\end{array}$ https://doi.org/10.1002/chem.201604812.

(17) Milan, D. C.; Vezzoli, A.; Planje, I. J.; Low, P. J. Metal Bis(Acetylide) Complex Molecular Wires: Concepts and Design Strategies. Dalton Trans. 2018, 47 (40), 14125-14138. https://doi.org/10.1039/C8DT02103A.
(18) Schwarz, F.; Kastlunger, G.; Lissel, F.; Egler-Lucas, C.; Semenov, S. N.; Venkatesan, K.; Berke, H.; Stadler, R.; Lörtscher, E. Field-Induced Conductance Switching by Charge-State Alternation in Organometallic Single-Molecule Junctions. Nature Nanotech 2016, 11 (2), 170-176. https://doi.org/10.1038/nnano.2015.255.

(19) For a molecular wire with a combination of redox and photoirradiation, see ref. 20 .

(20) Meng, F.; Hervault, Y.-M.; Shao, Q.; Hu, B.; Norel, L.; Rigaut, S.; Chen, X. Orthogonally Modulated Molecular Transport Junctions for Resettable Electronic Logic Gates. Nat Commun 2014, 5 (1), 3023. https://doi.org/10.1038/ncomms4023.

(21) Schauer, P. A.; Low, P. J. Ligand Redox Non-Innocence in Transition-Metal $\sigma$-Alkynyl and Related Complexes. Eur. J. Inorg. Chem. 2012, $2012 \quad$ (3), 390-411. https://doi.org/10.1002/ejic.201100995.

(22) Tanaka, Y.; Akita, M. Organometallic Radicals of Iron and Ruthenium: Similarities and Dissimilarities of Radical Reactivity and Charge Delocalization. Coord. Chem. Rev. 2019, 388, 334-342. https://doi.org/10.1016/j.ccr.2019.02.036.

(23) Fox, M. A.; Le Guennic, B.; Roberts, R. L.; Brue, D. A.; Yufit, D. S.; Howard, J. A. K.; Manca, G.; Halet, J.-F.; Hartl, F.; Low, P. J. Simultaneous Bridge-Localized and Mixed-Valence Character in Diruthenium Radical Cations Featuring Diethynylaromatic Bridging Ligands. J. Am. Chem. Soc. 2011, 133 (45), 18433-18446. https://doi.org/10.1021/ja207827m.

(24) Rigaut, S.; Perruchon, J.; Le Pichon, L.; Touchard, D.; Dixneuf, P. H. Synthesis of Ruthenium Acetylides: New Building Blocks for Molecular Electronics. J. Organomet. Chem. 2003, 670 (1), 37-44. https://doi.org/10.1016/S0022-328X(02)02101-0.

(25) Sugimoto, K.; Idei, H.; Tanaka, Y.; Akita, M. Synthesis and Charge Delocalization Property of Multimetallic Molecular Wires with Diethynylthiophene Bridges. J. Organomet, Chem. 2017, 847, 121-131. https://doi.org/10.1016/j.jorganchem.2017.02.033.

(26) Tanaka, Y.; Kato, Y.; Sugimoto, K.; Kawano, R.; Tada, T.; Fujii, S.; Kiguchi, M.; Akita, M. Single-Molecule Junctions of Multinuclear Organometallic Wires: Long-Range Carrier Transport Brought about by Metal-Metal Interaction. Chem. Sci. 2021, 12 (12), 4338-4344. https://doi.org/10.1039/D0SC06613C.

(27) Xu, B.; Tao, N. J. Measurement of Single-Molecule Resistance by Repeated Formation of Molecular Junctions. Science 2003, 301 (5637), 1221-1223. https://doi.org/10.1126/science.1087481.

(28) Hansch, Corwin.; Leo, A.; Taft, R. W. A Survey of Hammett Substituent Constants and Resonance and Field Parameters. Chem. Rev. 1991, 91 (2), 165-195. https://doi.org/10.1021/cr00002a004.

(29) Venkataraman, L.; Park, Y. S.; Whalley, A. C.; Nuckolls, C.; Hybertsen, M. S.; Steigerwald, M. L. Electronics and Chemistry: Varying Single-Molecule Junction Conductance Using Chemical Substituents. Nano Lett. 2007, 7 (2), 502-506. https://doi.org/10.1021/nl062923j.

(30) Yzambart, G.; Rincón-García, L.; Al-Jobory, A. A.; Ismael, A. K.; Rubio-Bollinger, G.; Lambert, C. J.; Agraït, N.; Bryce, M. R. Thermoelectric Properties of 2,7-Dipyridylfluorene Derivatives in Single-Molecule Junctions. J. Phys. Chem. C 2018, 122 (48), 27198 27204. https://doi.org/10.1021/acs.jpcc.8b08488. 
(31) Brandbyge, M.; Mozos, J.-L.; Ordejón, P.; Taylor, J.; Stokbro, K. Density-Functional Method for Nonequilibrium Electron Transport. Phys. Rev. B 2002, 65 (16), 165401. https://doi.org/10.1103/PhysRevB.65.165401.

(32) Tada, T.; Kondo, M.; Yoshizawa, K. Green's Function Formalism Coupled with Gaussian Broadening of Discrete States for Quantum Transport: Application to Atomic and Molecular Wires. J. Chem. Phys. 2004, 121 (16), 8050-8057. https://doi.org/10.1063/1.1799991.

(33) For detailed structures of molecular junction model, see SI.

(34) Wang, K.; Vezzoli, A.; Grace, I. M.; McLaughlin, M.; Nichols, R. J.; Xu, B.; Lambert, C. J.; Higgins, S. J. Charge Transfer Complexation Boosts Molecular Conductance through Fermi Level Pinning. Chem. Sci. 2019, 10 (8), 2396-2403. https://doi.org/10.1039/C8SC04199G.

(35) Thomas, G. A.; Schafer, D. E.; Wudl, F.; Horn, P. M.; Rimai, D.; Cook, J. W.; Glocker, D. A.; Skove, M. J.; Chu, C. W.; Groff, R. P.; Gillson, J. L.; Wheland, R. C.; Melby, L. R.; Salamon, M. B.; Craven, R. A.; De Pasquali, G.; Bloch, A. N.; Cowan, D. O.; Walatka, V. V.; Pyle, R. E.; Gemmer, R.; Poehler, T. O.; Johnson, G. R.; Miles, M. G.; Wilson, J. D.; Ferraris, J. P.; Finnegan, T. F.; Warmack, R. J.; Raaen, V. F.; Jerome, D. Electrical Conductivity of TetrathiafulvaleniumTetracyanoquinodimethanide (TTF-TCNQ). Phys. Rev. B 1976, 13 (11), 5105-5110. https://doi.org/10.1103/PhysRevB.13.5105.

(36) Demadis, K. D.; Hartshorn, C. M.; Meyer, T. J. The Localized-to-Delocalized Transition in Mixed-Valence Chemistry. Chem. $\begin{array}{lllll}\text { Rev. 2001, } & 101 & \text { (9), 2655-2686. }\end{array}$ https://doi.org/10.1021/cr990413m.

(37) Xie, L. S.; Sun, L.; Wan, R.; Park, S. S.; DeGayner, J. A.; Hendon, C. H.; Dincă, M. Tunable Mixed-Valence Doping toward Record Electrical Conductivity in a Three-Dimensional MetalOrganic Framework. J. Am. Chem. Soc. 2018, 140 (24), 7411-7414. https://doi.org/10.1021/jacs.8b03604.

(38) Ie, Y.; Okamoto, Y.; Inoue, T.; Seo, T.; Ohto, T.; Yamada R.; Tada, H.; Aso, Y. Improving Intramolecular Hopping Charge Transport via Periodical Segmentation of $\pi$-Conjugation in a Molecule. J. Am. Chem. Soc. 2021, 143 (2), 599-603. https://doi.org/10.1021/jacs.0c10560.

(39) Naitoh, Y.; Ohata, T.; Matsushita, R.; Okawa, E.; Horikawa, M.; Oyama, M.; Mukaida, M.; Wang, D. F.; Kiguchi, M.; Tsukagoshi, K.; Ishida, T. Self-Aligned Formation of Sub 1 Nm Gaps Utilizing Electromigration during Metal Deposition. ACS Appl. Mater. Interfaces 2013, 5 (24), 12869-12875. https://doi.org/10.1021/am403115m.
(40) Probably Due to the Large Size of BARF Salt, No Resistance Change Was Observed before and after Immersion in [1H][BARF].

(41) Nie, S.; Emory, S. R. Probing Single Molecules and Single Nanoparticles by Surface-Enhanced Raman Scattering. Science 1997. https://doi.org/10.1126/science.275.5303.1102.

(42) Suzuki, S.; Kaneko, S.; Fujii, S.; Marqués-González, S.; Nishino, T.; Kiguchi, M. Effect of the Molecule-Metal Interface on the Surface-Enhanced Raman Scattering of 1,4-Benzenedithiol. J. Phys. Chem. C 2016, 120 (2), 1038-1042. https://doi.org/10.1021/acs.jpcc.5b10385.

(43) Langer, J.; Jimenez de Aberasturi, D.; Aizpurua, J.; Alvarez-Puebla, R. A.; Auguié, B.; Baumberg, J. J.; Bazan, G. C.; Bell, S. E. J.; Boisen, A.; Brolo, A. G.; Choo, J.; Cialla-May, D.; Deckert, V.; Fabris, L.; Faulds, K.; García de Abajo, F. J.; Goodacre, R.; Graham, D.; Haes, A. J.; Haynes, C. L.; Huck, C.; Itoh, T.; Käll, M.; Kneipp, J.; Kotov, N. A.; Kuang, H.; Le Ru, E. C.; Lee, H. K.; Li, J.-F.; Ling, X. Y.; Maier, S. A.; Mayerhöfer, T.; Moskovits, M.; Murakoshi, K.; Nam, J.M.; Nie, S.; Ozaki, Y.; Pastoriza-Santos, I.; Perez-Juste, J.; Popp, J.; Pucci, A.; Reich, S.; Ren, B.; Schatz, G. C.; Shegai, T.; Schlücker, S.; Tay, L.-L.; Thomas, K. G.; Tian, Z.-Q.; Van Duyne, R. P.; Vo-Dinh, T.; Wang, Y.; Willets, K. A.; Xu, C.; Xu, H.; Xu, Y.; Yamamoto, Y. S.; Zhao, B.; Liz-Marzán, L. M. Present and Future of Surface-Enhanced Raman Scattering. ACS Nano 2020, 14 (1), 28-117. https://doi.org/10.1021/acsnano.9b04224.

(44) We measured SERS measurement by the commercial laser Raman spectrometer (NRS 4500, JASCO Corporation, Japan). The wavelength and power of the excitation laser were $785 \mathrm{~nm}$ and $3 \mathrm{~mW}$

(45) The normal Raman spectrum of the $\mathbf{1}^{\mathbf{H}}$ was obtained with the laser irradiation of $20 \mathrm{~s}$. The intensity of the vibrational mode observed at $1175 \mathrm{~cm}^{-1}$ were mapped with the resolution of $3 \mu \mathrm{m}$. The mapping area is $12 \mu \mathrm{m} \times 42 \mu \mathrm{m}$.

(46) Liu, I. P.-C.; Bénard, M.; Hasanov, H.; Chen, I.-W. P.; Tseng, W.-H.; Fu, M.-D.; Rohmer, M.-M.; Chen, C.; Lee, G.-H.; Peng, S.-M. A New Generation of Metal String Complexes: Structure, Magnetism, Spectroscopy, Theoretical Analysis, and Single Molecular Conductance of an Unusual Mixed-Valence Linear [Ni5]8+ Complex. Chem. Eur. J. 2007, 13 (31), 8667-8677. https://doi.org/10.1002/chem.200700750

(47) Ting, T.-C.; Hsu, L.-Y.; Huang, M.-J.; Horng, E.-C.; Lu, H.-C.; Hsu, C.-H.; Jiang, C.-H.; Jin, B.-Y.; Peng, S.-M.; Chen, C. Energy-Level Alignment for Single-Molecule Conductance of Extended MetalAtom Chains. Angew. Chem. Int. Ed. 2015, 127 (52), 15960-15964. https://doi.org/10.1002/ange.201508199. 